\title{
Corrigendum
}

\section{The oncolytic compound LTX-401 targets the Golgi apparatus}

\author{
Heng Zhou, Allan Sauvat, Lígia C Gomes-da-Silva, Sylvère Durand, Sabrina Forveille, Kristina Iribarren, Takahiro Yamazaki, \\ Sylvie Souquere, Lucillia Bezu, Kevin Müller, Marion Leduc, Peng Liu, Liwei Zhao, Aurélien Marabelle, Laurence Zitvogel, \\ Øystein Rekdal, Oliver Kepp and Guido Kroemer
}

Cell Death and Differentiation (2018) 25, 227-228; doi:10.1038/cdd.2017.148; published online 10 November 2017

Correction to: Cell Death and Differentiation (2016) 23, 2031-2041; doi:10.1038/cdd.2016.86; published online 2 September 2016

Since the publication of this paper, we have noted that the images shown for the untreated cell (control, CTR) in Figure 2d were identical at 5 and $6 \mathrm{~h}$.

We deplore this unintentional error that arose while cropping the film of the untreated and hence rather inert cell. We include a corrected Figure $2 \mathrm{~d}$ showing a full sequence of an untreated cell. In the Supplementary material, three films demonstrating an entire view field containing multiple cells are included. These films have been obtained in untreated conditions, as well as after exposure of cells to LTX-315 or LTX-401, as specified in the legend to Figure $2 \mathrm{~d}$ as well as in the Materials and Methods. Interested readers will appreciate the capacity of LTX-401 to dissipate the green fluorescent signal (corresponding to the Golgi apparatus), contrasting with the untreated control, as well as LTX-315treated cells. Please note that the conclusions of the paper are not affected.

The corrected article appears online together with this corrigendum. We apologise for any inconvenience this may have caused. 
a

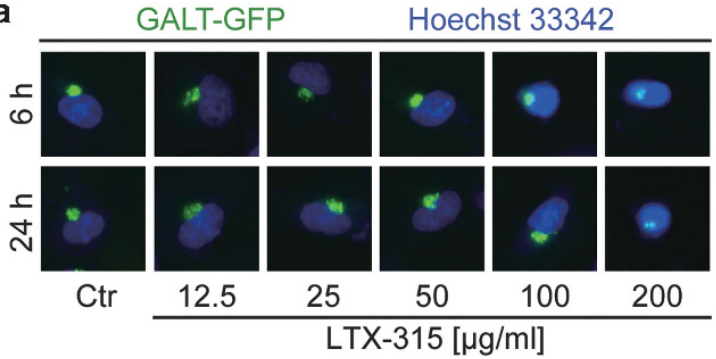

GALT-GFP Hoechst 33342

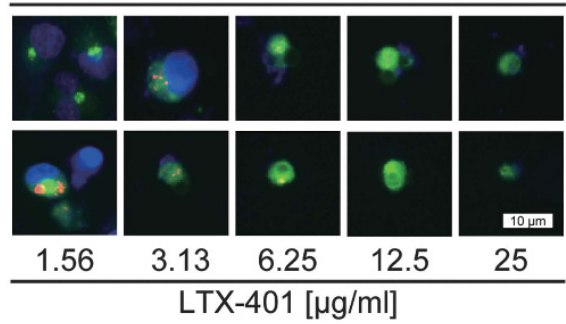

b
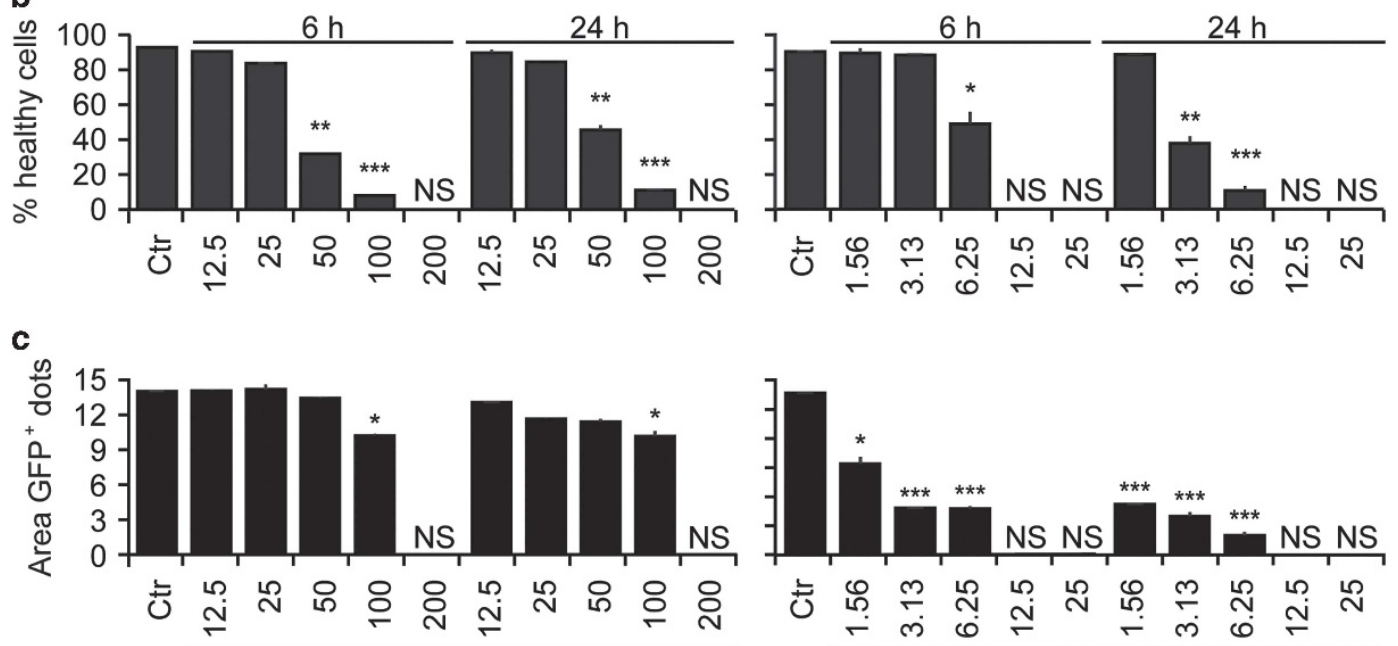

LTX-315 [ $\mu \mathrm{g} / \mathrm{ml}]$

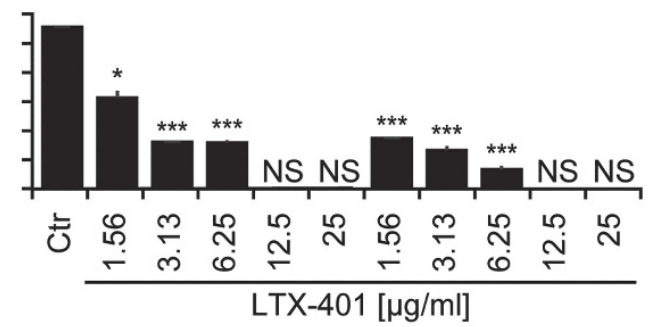

d
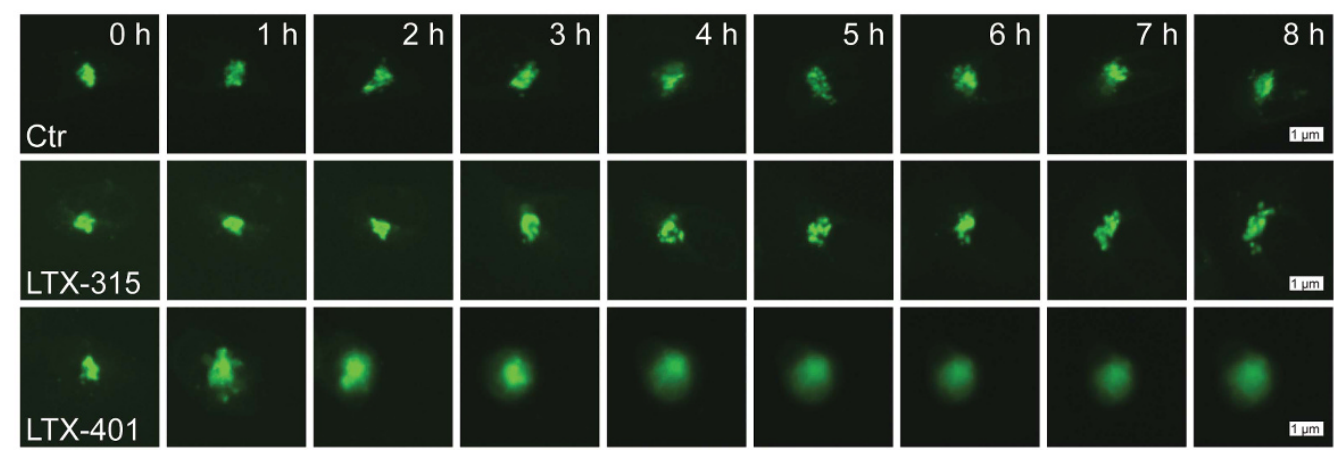

Figure 2 Differential effects on Golgi morphology induced by LTX-315 and LTX-401. (a) U2OS cells stably expressing GALT1-GFP were treated for the indicated period with the indicated concentrations, which covered the half maximum toxic effect, of LTX-315, or LTX-401, followed by fixation and nuclear counterstaining with the DNA intercalating dye Hoechst 33342. Representative images are shown in (b). Quantitative results (means \pm S.D. of triplicates) for viability and Golgi fragmentation are shown in (b and $\mathbf{c}$ ), respectively. In (b), the number of cells with normal nuclear morphology (not shrunken) is shown, while in (c), the average area of GALT1 ${ }^{+}$Golgi structures per cell is displayed. (d) Time-lapse microscopy of U2OS cells stably expressing GALT1-GFP cells treated with $50 \mu \mathrm{g} / \mathrm{ml} \mathrm{LTX-315} \mathrm{or} 6.25 \mu \mathrm{g} / \mathrm{ml}$ LTX-401 (that had similar effects on viability) showed the time-dependent fragmentation of the Golgi in one representative cell in response to LTX-401 but not to LTX-315. Asterisks indicate significant differences (unpaired Student t-test) with respect to untreated controls. ${ }^{*} P<0.05 ;{ }^{* *} P<0.01 ;{ }^{* *} P<0.001$ 